\title{
DOS PERIGOS DA CIDADE AOS RISCOS DO URBANISMO: COMO OS CONCEITOS DE COMPLEXIDADE, RISCO E SISTEMA EM NIKLAS LUHMANN AJUDAM A DISCUTIR O FUTURO DO URBANISMO
}

\author{
João Julio V. Amaro ${ }^{1}$
}

\begin{abstract}
Resumo: O âmago da teoria de Luhmann é a comunicação. Toda comunicação no interior de um sistema opera pela seleção e processamento de apenas uma quantidade limitada de informações disponíveis de fora. Cada sistema trabalha estritamente em seus próprios códigos e sem acordo sobre os modos como outros sistemas percebem seu entorno. Niklas Luhmann desenvolve um programa teórico para exame desta questão. Sua premissa é que o conceito de risco projeta, no presente, aspectos essenciais de nossa descrição do futuro. Risco é concebido como a possibilidade de uma decisão desencadeadora de consequências improváveis, inesperadas e prejudiciais, ser atribuída aos tomadores de decisão. Assentados nessa teoria, discutimos uma abordagem para explorar a complexidade do sistema urbano.

Palavras-Chave: Complexidade, Teoria de sistema, Risco.
\end{abstract}

Abstract: The core element of Luhmann's theory is communication. All communication within a system operates by selecting and processing only a limited amount of all information available outside. Each system works strictly according to its very own code and has no understanding at all for the way other systems perceive their environment. Niklas Luhmann develops a theoretical program for such research. His premise is that the concept of risk projects essential aspects of our description of the future onto the present. Risk is conceived as the possibility of triggering unexpected, unlikely, and detrimental consequences by means of a decision attributable to a decision maker. Based on this theory, we introduce an approach to exploit the complexity of an urban system.

Keywords: Complexity, System theory, Risk.

O urbanismo risca e arrisca. Antecipar o futuro não é tarefa promissora. É arriscado. Quem disso se ocupa se apresenta ao crivo das próximas gerações sempre dispostas a ver um mero devaneio onde o autor, na meIhor das boas intenções, diluiu alguns sinais que lhe foi oportuno interpretar como um seguro endereçamento ao futuro. Assim é o urbanismo: ter que riscar agora o chão onde vão morar não se sabe ainda quantos, nem

1 Arquiteto; Doutor pela Technische Universität Berlin; Prof. Associado do Dep. de Urbanismo da Escola de Arquitetura da Universidade Federal de Minas Gerais (UFMG). Endereço eletrônico: juliovitral@yahoo.com.br. 
quem e menos se sabe qual tipo de metabolismo nossos pósteros imporão à terra. Se dos riscos do urbanismo se erige em pedra a conformação da sociabilidade futura, não se pode deixar de fazer a pergunta - sem resposta no presente - sobre o ônus para as gerações futuras dos delírios aos quais, levemente, nos entregamos. São muitos os perigos do urbanismo.

Risco e perigo, risco ou perigo, risco ou segurança: em dupla, as palavras vão encontrando meios de se escorar umas nas outras. Assim uma palavra se defende, acentua e resguarda, pela diferença com seu par, sua pretensão de unicidade. Ser único apenas na diferença frente ao outro: unicidade relativa, incompleta ou a ser completada na copresença do outro. Essa operação simultânea de demarcação e distinção, levada a efeito pela diferença, encontra sua forma mais pura na cibernética. A diferença é o âmago da cibernética: "a difference which makes a difference" (BATESON, 2000). A intransigente declaração de que sou isso e não aquilo vibra pelos circuitos elétricos de um computador. O código binário é implacável: é isso e não aquilo. Pelas correntes elétricas, permite-se um só comando: ligado ou desligado, positivo ou negativo, sim ou não. Na trama de caminhos que se bifurcam, só se entra pela esquerda ou pela direita. As interdições se dão uma a uma e, de cada vez, a inevitabilidade de uma única escolha se impõe. A primeira escolha (diferença) empurra para e segunda, da segunda para a terceira... criando-se a alta complexidade que assim fica definida como emergência. Emergência é o processo de formação de modelos complexos a partir de regras simples. Isso vale tanto para os processos psíquicos quanto para os sociais, para os neurônios quanto para organizações (universidades ou usinas hidrelétricas) ${ }^{2}$.

Tudo se passa como se a cibernética registrasse as formas mais puras de realização das insondáveis operações da consciência. Se isso é verdade por que então não fazer o caminho de volta? Como num Gedankenexperiment, acessar a "consciência social" pelas operações cibernéticas! Desse modo, reconstruir as operações, expor os mecanismos pelos quais a sociedade "pensa", é o mesmo que reconstituir, na linguagem de uma codifica-

2 Sistemas nervosos, sistemas psíquicos e sistemas sociais formam diferentes ordens que mantêm entre si a relação de ambiente, entorno, uns para os outros. É conveniente lembrar que a palavra usada por Luhmann para designar o entorno de um sistema é a palavra alemã Umwelt, que também é traduzida entre nós por ambiente (LUHMANN 1987). Embora a palavra alemã Umwelt seja usada como usamos "meio-ambiente" na língua portuguesa, no sentido de ecologia; o Umwelt como o "outro" do sistema é mais amplo, pode designar meio-ambiente como também tudo aquilo "fora" do sistema.

Número temático: Desenho e Educação: Cultura Visual e Cidade. A Cor das Letras - UEFS, $n$. 
ção binária, a emergência de semânticas com as quais a sociedade fala de si mesma ou, na expressão de Luhmann, "descreve a si mesma" (LUHMANN, 1987). Se a consciência faz do pensamento sua operação genuína, a sociedade tem exclusividade na comunicação. A sociedade comunica. Apenas ela comunica. Se a consciência produz pensamentos de pensamento, a sociedade produz comunicação de comunicação ${ }^{3}$.

Para a teoria de sistemas, a aproximação do fenômeno social com a cibernética não é apenas um apelo a uma simples analogia. Não são apenas as semelhanças entre máquinas (para nos atermos à referência mais corriqueira quando a palavra cibernética é lembrada) e sociedade que instalam a possibilidade de um mesmo linguajar. As sociedades também operam em sistemas de códigos e programas e, a partir deles, podem ser examinadas, dentre outras, as questões urbanas e ambientais e as representações que as várias formas sociais fazem delas. Obviamente que se trata aqui de um processo relacionado com a construção da vida social, com a coesão e permanência de processos que interligam indivíduos em suas várias dimensões ou, ainda, no jargão do marxismo, no plano material e ideológico. Esse processar em códigos se distribui por toda a sociedade por seus sistemas (jurídico, econômico, religioso, científico, educacional, artístico etc.). Para a teoria de sistemas, o sistema econômico (com o processar de seus códigos internos), ao contrário do que pretende a teoria marxista, não é a base a

3 Para descrever processos relacionados à neurofisiologia, Maturana (2002), biólogo chileno, adotou o neologismo autopoiesis, que rapidamente se difundiu pela vertente epistemológica do construtivismo, com destaque na teoria de sistema. Maturana (2002) examina processos cognitivos a partir do funcionamento do cérebro. $O$ cérebro funciona em regime de clausura operacional; quer dizer, não é "programável" de fora; suas operações são uma auto-produção. Isso ocorre nos sistemas biológicos em geral e pode ser ilustrado pela vida de uma célula, como o faz Varela, outro biólogo que trabalha em estreita cooperação com Maturana (VARELA 1990). Pode-se entender que uma célula é o menor sistema vivo; isto é, uma organização que preserva a si mesma como resultado de sua organização. Isso quer dizer que ela produz componentes que produzem componentes que produzem componentes: enzimas produzem enzimas. O limite da célula é sua membrana. A membrana é o processo que limita a difusão e assim preserva a rede de produção que produz a membrana. Do mesmo modo que os sistemas vivos são caracterizados pela autopoiesis, também os sistemas psíquicos e os sistemas sociais se individualizam na sua auto-referência: nos processos psíquicos, pensamentos são feitos de pensamentos e nos processos sociais comunicação é feita de comunicação. A comunicação é a operação específica que identifica os sistemas sociais: não existe sistema social que não tenha como operação própria a comunicação, e não existe comunicação fora dos sistemas sociais. 
partir da qual todos os outros seriam explicados. Não há sistemas subordinados a outros ou a uma superconsciência ("esfera pública", partido político, opinião pública, mídia etc.) capaz de coordenar ou "programar" todas as outras. Quer dizer, não há um ponto central a partir do qual a sociedade possa observar e descrever a si mesma.

Assim, pode-se perguntar pelo lugar compartilhado pelo urbanismo no conjunto da observação que a sociedade faz de si mesma. Ainda há lugar reservado ao urbanismo no futuro que a sociedade faz (observa) de si mesma? Dizer que a sociedade observa a si mesma é inapropriado. Nada pode observar a si mesmo a não ser numa duplicação de si mesmo quando se faz observado e observador. A teoria de sistema, quando se refere à observação da sociedade sobre si mesma, está se referindo a um sistema (que observa) e um ambiente (ao qual o sistema que observa considera "a sociedade"). Toda observação é sistema. Assim, um sistema que se erige em ponto de observação da sociedade não "vê" toda a sociedade, mas "vê apenas o que ele pode ver" (MATURANA, 2002). Não é excluída a possibilidade de que outro observe aquele observador que "não vê o que ele não pode ver". Essa segunda possibilidade, a observação de um observador, é chamada, na cibernética, de "observação de segunda ordem".

Assim, com origem na cibernética e na teoria construtivista, o conceito de observação é um dos conceitos centrais na teoria de sistemas. Bastante à vontade para colocar em questão até mesmo a realidade do chão em que pisam, os construtivistas estão antes interessados na criação da realidade mesma pelos processos psíquicos: "Tudo que é dito, é dito por um observador" (MATURANA, 2002). Até mesmo o tempo, esse conceito filosófico arredio, tão facetado de Aristóteles a Santo Agostinho, é definido por diferenças trazidas pela observação. "As representações sobre o tempo não têm objeto independente da observação. Elas, como observações e descrições de relações temporais, são observações e descrições no tempo. Daí poder-se concluir que elas são dependentes da sociedade que comunica sobre o tempo e desenvolve formas apropriadas para isso" (LUHMANN, 2003, p. 41). Não há por que perder tempo se ocupando, virtualmente, de tudo. Há que se fazer seleção sobre aquilo (e não aquilo outro) que se quer. Na própria ideia de tempo há que se fazer uma seleção: de que tempo falamos? Do tempo que se nos oferece pela distinção passado-presente ou pela distinção imóvel-móvel? São duas semânticas do tempo. Semânticas sociais das quais a última (imóvel-móvel) é própria das sociedades nobiliár- 
quicas, por exemplo, onde se distingue aquilo que permanece (os títulos, os privilégios) frente ao efêmero, ou seja, ao restante da sociedade.

O horizonte temporal das sociedades pré-modernas ocidentais ligava-se à concepção de movimento, fundamentalmente, pela distinção tempo-eternidade. A eternidade indicava a posição divina, da qual emanava o tempo, e garantia a origem de tudo. Daí distinguia-se o tempo finito da criação, aquele que tem um começo e um fim, cujo sentido só se encontra na eternidade. Para as sociedades funcionalmente diferenciadas (modernas, não mais estratificadas ou diferenciadas por títulos), o movimento é substituído pela ideia de presente, quando o passado e o futuro incerto, contingente e aberto se projetam, onde o passado é a seleção feita de acordo com uma recombinação pelo endereçamento ao futuro. Assim, a partir do século XVIII, a História (Geschichtsschreibung) é entendida como autorreferencial, a recombinação de dados e fatos, dependendo de quais princípios teóricos são adotados. A História torna-se histórica (LUHMANN, 1987, p. 216).

Se a sociedade, na sua representação de tempo, se faz histórica, concebendo o passado como o pressuposto do presente, o futuro torna-se o peso do presente, como risco. O conceito de risco se distingue do conceito de perigo. Risco relaciona-se com a decisão de se precaver contra possíveis danos futuros. É uma forma de vinculação com o tempo (Zeitbindung, time binding) que a sociedade assume ao decidir, no presente, o controle de suas próprias mudanças, de seu fluxo passado-presente-futuro. As decisões, no presente, condicionam aquilo que acontecerá no futuro sem que se saiba ao certo como isso vai acontecer. As decisões têm de ser tomadas sem conhecimento suficiente do futuro, fazendo, assim, que não se tenha nenhuma proteção de eventuais danos causados pela própria decisão. 0 comportamento de risco é caracterizado pela inevitabilidade da decisão: não se pode deixar de decidir (LUHMANN, 1987, p. 161).

Frente aos perigos, as sociedades desenvolvem dispositivos para defesa ou reação, de acordo com suas capacidades tecnológicas, o grau de ameaça e a possibilidade de previsão internalizada por experiências passadas de eventos catastróficos. Toda essa capacidade de mobilização depende de características específicas de cada sociedade. Assim, é possível descrever as sociedades por meio da reação aos eventos que rompem com as expectativas de regularidade da vida social. Isso porque todos os recursos mobilizados, como a capacidade tecnológica, a visibilidade de ameaças e a intromissão de experiências passadas no balizamento dos eventos catastró- 
ficos, indicam o arcabouço por meio do qual as sociedades veem ou interpretam a si mesmas. Pode-se dizer que uma sociedade é um processamento regular, uma tradução, para seus próprios parâmetros, das ameaças que estão "fora" dela. Aquilo que está fora dela é decidido por ela mesma; ou ainda, decidir o que está fora é atribuição apenas dela, é uma "construção" que, "correta" ou não, afasta uma programação externa, de fora dos próprios códigos com os quais a sociedade opera. Aqui é conveniente lembrar que sociedade é o conjunto dos sistemas da sociedade: não há ponto privilegiado a partir do qual a sociedade possa, antevendo o futuro, reagir.

A esta altura, podemos nos perguntar por quais dobras ou intersecções dos sistemas da sociedade o pensamento urbanístico faria ouvir sua notificação sobre o tempo. Como o tempo "entra" na sociedade ou como os sistemas sociais veiculam suas próprias semânticas do tempo de modo a poder desaguar no pensamento urbanístico? Podemos esboçar um início de resposta, destacando a hegemonia do discurso da economia na descrição que a sociedade faz de si mesma. É como se quase tudo devesse ser balizado pela economia para contabilizar lucros ou prejuízos. Seja a respeito do furacão Katrina que atingiu New Orleans ou dos quilométricos engarrafamentos cada vez mais frequentes nas grandes cidades. Sobre os grandes engarrafamentos, são mencionadas as horas paradas e os consequentes prejuízos, medidos como perdas monetárias. Mas, como todo sistema, o sistema da economia é autorreferente. Assim, para ser consequente, a fala da economia teria de dizer que, se não houvesse tal prejuízo, o dinheiro não perdido nas horas paradas nos engarrafamentos serviria para comprar mais... automóveis! A autorreferência leva a paradoxos, aos confins do sistema, onde o sistema trava.

Embora insuficiente, a economia ou, melhor dizendo, o discurso da economia (ou, ainda, na linguagem da teoria de sistemas, a observação do sistema da ciência sobre o sistema econômico) é um grande reservatório semântico que a sociedade moderna tem para falar de si mesma. Não que a semântica da economia tenda à hegemonia nas sociedades modernas como consequência da suposta prevalência ou sobredeterminação do econômico (como pretende o marxismo) sobre as demais esferas da vida social. O que é possível que ocorra, nas sociedades modernas, é a maior decantação do discurso da economia, das representações que se fazem da economia no seu distanciamento do discurso religioso; decantação esta que não ocorre na mesma intensidade frente, por exemplo, ao discurso jurídico. O próprio linguajar corrente em várias esferas da vida social, que se utiliza de expres-

84 Número temático: Desenho e Educação: Cultura Visual e Cidade. A Cor das Letras - UEFS, n. 
sões como "justiça econômica", "preço justo", "economia solidária" etc., atesta essa contaminação semântica entre sistemas, ou a transposição de códigos de uns sistemas para outros; no caso, para a economia. Não por acaso, as questões ambientais, contidas até então em repertórios de sistemas específicos, são sinalizadas no discurso da economia, embora não seja novidade na história do pensamento econômico a tematização do desenvolvimento relacionado com os limites dos recursos naturais.

O urbanismo, acossado pela pretensão totalizante da economia e, com isso, tendo de oferecer respostas nos termos em que a economia coloca o problema, encontra ainda a enorme barreira da alta tecnologia a limitar seu alcance, demarcar seu próprio território, sua área de manobra. Se entendermos genericamente como cidade a disposição de pessoas habitando sobre uma mesma superfície e compartilhando serviços e responsabilidades comuns, veremos que o funcionamento do aparato físico dessa teia de relações é controlado por uma grande variedade de agências altamente especializadas. Esse aparato físico, ou as tecnologias da cidade, sustenta as redes de abastecimento alimentar, transporte, coleta e destinação do lixo, provisão de água e energia elétrica etc. São processos físicos cujo funcionamento é assentado na seleção de relações causais. Toma-se das várias possibilidades de interação dos elementos naturais (alta complexidade) uma única cadeia de relações para, por exemplo, canalizar a água para dentro das casas. Essa redução de complexidade requer, em troca, a complexidade do controle desse fluxo, dessa cadeia causal "canalizada".

Luhmann distingue grande tecnologia de alta tecnologia. A primeira diz respeito aos problemas de sobrecarga, do dimensionamento, dos problemas de gestão que derivam do funcionamento de redes ferroviárias, redes de abastecimento, linhas telefônicas, redes de comunicação em geral etc., coisas sem muito interesse frente à questão da técnica como redução funcional, como imposição incontornável do aumento da complexidade social. A alta tecnologia diz respeito ao emaranhamento da tecnologia no interior dos sistemas sociais que torna sempre obrigatória a decisão sobre a tecnologia, mas já no interior das possibilidades prescritas pela própria tecnologia (LUHMANN, 1987). Não há caminho de volta. Uma vez tendo-se decidido pela redução da complexidade (na escala elevada exigida pela alta complexidade social), pela baixa entropia da matéria organizada e dirigida a fins específicos, menos chance haverá para caminhos alternativos. É como se fossem trilhos a estar sempre em construção, cujas bitolas são definidas 
de antemão (por uma decisão anterior) e, portanto, excluindo outras, para suportar um corpo que se move inapelavelmente sempre para frente.

A técnica é comumente pensada como o oposto da natureza, como o artificial contraposto ao natural. Fazer essa diferença era comum nos anos 1970, no início do movimento ambientalista. Essa diferença era muito importante na mobilização contra os chamados defensivos agrícolas, acentuando a técnica em contraste com a natureza, esta interpretada como mais saudável, mais de acordo com o "equilíbrio" ecológico. Ressonâncias desses posicionamentos aparecem hoje nos protestos contra, por exemplo, a manipulação genética da soja. Os riscos da tecnologia da produção alimentar (distintos dos perigos da contaminação por agrotóxicos) dizem respeito ao encadeamento causa-efeito projetado. Projetado para a redução da complexidade que, do contrário, ficaria à mercê, por exemplo, das contingências ligadas aos cataclismos naturais.

A tecnologia, como "simplificação orientada para um fim" ou "redução de complexidade" (LUHMANN, 2003, p. 105), como decisão sobre umas e não outras das tantas relações causais, significa não apenas o necessário abandono de possibilidades, mas também o enquadramento das possibilidades futuras. A técnica é, para Luhmann, "a simplificação funcional num dado conjunto de relações causais". Toda decisão relacionada à alta tecnologia envolve risco. A decisão sobre geração de energia por usinas nucleares leva o problema da atividade radioativa dos dejetos para, no mínimo, mil anos à frente. A decisão em não se ter usina nuclear entrega também ao futuro o problema da escassez de recursos para a geração de energia.

As consequências da teoria podem ser mais bem ilustradas, considerando uma sociedade que, por algum de seus sistemas, observa a si mesma, delimitando seu entorno na comunicação sobre, por exemplo, abastecimento alimentar. Esta observação da sociedade sobre si mesma significa, na linguagem corrente, que a referida sociedade, em algum nível, tematiza o problema alimentar; não significando, com isso, que toda a sua complexidade se reduza à questão da alimentação. Sua complexidade interna, no entanto, vai filtrar a complexidade do entorno ou ambiente na tentativa de extrair daí soluções para o seu problema de abastecimento. Seu entorno será de um tipo se for uma sociedade sem nenhum conhecimento tecnológico e será de outro tipo se sua tecnologia for capaz de aumentar a produtividade natural do solo: para o mesmo solo natural, dois ambientes diferentes, pois são duas distinções. O desenvolvimento tecnológico amplia a possibilidade do entorno em proveito do sistema social. Essa tecnologia é, 
no entanto, o filtro a partir do qual a complexidade do entorno será reduzida ou processada. A redução da complexidade significa, no entanto, o aumento da complexidade interna ao sistema ${ }^{4}$. A produção alimentar será feita por uns meios (tecnológicos) e não por outros (abandonando parte da complexidade do entorno), e a decisão sobre os meios escolhidos aumentará a complexidade interna do sistema social: redução de complexidade é, para o sistema, aumento de complexidade.

O sistema (ou um dos sistemas da sociedade) pode distinguir risco pela codificação binária "risco/segurança", na distinção do risco enquanto situação outra que não a segurança. Esta é, no entanto, uma distinção banal, pouco capaz de estimular a exploração do tema; e talvez, por sua trivialidade, favoreça os discursos dos políticos quando querem se passar por depositários da segurança pública. Luhmann propõe a distinção "risco/perigo" como a mais apta para desenvolver o tema risco nas sociedades complexas. Como na teoria de sistema, as distinções são feitas por observadores, é possível que, para a grande maioria, para as (potenciais) vítimas, as (possíveis) catástrofes apareçam como perigo, como fatalidades, como um processar de leis naturais impossível de ser previsto. Para os tomadores de decisão, para os que mobilizam técnicas de previsão ou de prevenção, as consequências das decisões aparecem como risco. Não se trata aqui de uma dramatização da relação culpados/vítimas, na qual os tomadores de decisão seriam os culpados por decisões erradas. A questão tratada por Luhmann é mais sutil e aponta para características únicas das sociedades modernas dotadas de crescente sofisticação tecnológica: as decisões são imprescindíveis (LUHMANN, 1987). As sociedades estão tão entranhadas pela alta tecnologia que o simples fato de se renunciar a uma decisão é também uma decisão.

A partir da exploração dos conceitos da cibernética desenvolvida por Luhmann, é possível considerar de novos ângulos a questão do risco ambi-

4 Em um sistema social, nem tudo pode estar atualizado; são feitas reduções a partir da necessidade de se manter uma complexidade interna que se faça compatível o sistema com relação ao entorno. Redução de complexidade significa que uma estrutura de relações entre elementos (de um sistema ou do entorno) se reconstrói em um número menor de relações em um sistema particular. A complexidade se realiza e se mantém em um sistema só mediante reduções. Sendo assim, redução e manutenção da complexidade se necessitam mutuamente. Redução de complexidade significa a permanência seletiva num conjunto de possibilidades em bases estruturais. São as estruturas que determinam quanta complexidade interna um sistema pode criar e tolerar. $O$ conceito de estrutura indica, portanto, a seleção das relações entre elementos admitidos em um sistema. 
ental e particularmente daqueles riscos relacionados às cidades. A rigor, Luhmann não especifica o tipo de risco tratado em sua teoria como risco ambiental exclusivamente. Como a caracterização do risco não é exclusiva de um conjunto de fatos assemelhados, interpretados como ameaça, mas se estende à consideração do entorno (ambiente) da vida social, os conceitos aí elaborados podem ser trazidos para o exame da questão urbana em suas várias dimensões. Como foi mostrado, o risco relaciona-se com a decisão de se precaver contra possíveis danos futuros. É uma forma de vinculação com o tempo, que a sociedade assume ao decidir, no presente, o controle de suas próprias mudanças.

Do mesmo modo, tematizadas como risco, estão outras formas de controle de mudanças que a sociedade exerce em vista de um futuro improvável. As normas e normatizações, veiculadas pelo sistema jurídico, estabilizam expectativas. Não conduzem, nem garantem comportamentos, mas exercem um poder limitador daquilo que, no correr do tempo, pode ser esperado; quer dizer, limitam e discriminam aquilo que se deve esperar daquilo que a sociedade não pode tolerar. Com normatizações, procura-se garantir uma estabilidade frente à insegurança inerente ao futuro. Junto com os procedimentos (jurídicos), as normas são, na linguagem de Luhmann, programas que permitem a operatividade do código binário do sistema do direito, lícito-ilícito (LUHMANN, 1987, p. 148). Nesta base de operação, estão possíveis riscos já que são colocadas limitações de futuras possibilidades de comportamentos (com discriminação e criminalização) sem que se saiba, de antemão, a futura tolerância social para determinados comportamentos. O sistema do direito, por exemplo, discrimina e decide a favor de um, contra o outro, e sua decisão se estende para um futuro ainda não visível (LUHMANN, 1987, p. 147).

O urbanismo tem sua operatividade (o processo de consolidação da cidade de acordo com um plano) garantida pelas normas (conjunto de códigos reguladores de construções, repartição do solo para várias funções, definição de público e privado etc.) e, com isso, não está isento dos riscos de o plano não corresponder às expectativas futuras. No entanto, esse risco é cada vez mais compartilhado por outros sistemas como aqueles moldados pela alta tecnologia: sistemas que assumem várias partes do funcionamento das cidades, deixando o urbanismo como prática residual nos interstícios de outros sistemas. Cada vez mais, o urbanismo não se faz distinguir como o locus de onde a sociedade se arremete ao futuro. Esvaziado pelas técnicas da engenharia de tráfego, coleta e destinação do lixo, abastecimento, etc. o 
urbanismo sobrevive sofregamente já que as decisões sobre o urbano são localizadas em outros sistemas.

Assim, as decisões sobre o urbano são "técnicas" uma vez que, da atuação dos sistemas (conformados pela alta tecnologia) impulsiona-se um arremesso irreversível para frente, inegociável ou, pelo menos, não negociado cotidianamente. Instalam-se outros tempos, outras representações de tempo, que recortam e isolam as iniciativas políticas que, doravante, se restringirão apenas a acusar os déficits do sistema. Assim como o urbanismo - menos apto a responder pelo futuro da cidade - as representações que se fazem dele, resignadas, estão longe de alçá-lo à situação de perscrutador do futuro. Perguntar pelo futuro do urbanismo é perguntar pela disposição ou por quais meios (ou operações, na linguagem da teoria de sistema) a sociedade ainda pergunta pelo futuro.

\section{REFERÊNCIAS}

BATESON, G. Steps to an Ecology of Mind. Chicago: University of Chicago Press, 2000.

LUHMANN, N. Oekologische Kommunikation. [Comunicação ecológica]. Wiesbaden: Verlag für Sozialwissenschaften, 2004.

LUHMANN, N. Soziologie des Risikos. [Sociologia do risco]. Berlin: Walter de Gruyter, 2003.

LUHMANN, N. Die Wissenschaft der Gesellschaft. [A ciência da sociedade]. Frankfurt am Main: Suhrkamp, 1992.

LUHMANN, N. Soziale Systeme. [Sistemas sociais]. Frankfurt am Main: Suhrkamp, 1987.

MATURANA, H. A ontologia da realidade. Belo Horizonte: Ed. UFMG, 2002.

VARELA, F. Kognitionswissenschaft - Kognitionstechnik. [Ciência cognitiva - técnica cognitiva]. Frankfurt am Main: Suhrkamp, 1990. 
